p-ISSN 2615-787X e-ISSN 2615-790X

Accredited by Directorate General of Research and Development Strengthening No: 36b/E/KPT/2016
Tropical Animal Science Journal, December 2018, 41(3):185-190 DOI: https://doi.org/10.5398/tasj.2018.41.3.185 Available online at http://journal.ipb.ac.id/index.php/tasj

\title{
In Vitro and in Vivo Anthelmintic Activities of Aqueous Leaf Infusion of Azadirachta indica against Haemonchus contortus
}

\author{
A. A. Sakti ${ }^{a, b}$, Kustantinah $^{\mathrm{b}, *}$, \& R. W. Nurcahyo ${ }^{c}$ \\ ${ }^{a}$ Research Unit for Natural Product Technology, Indonesian Institute of Sciences \\ Jalan Yogya-Wonosari Km 31,5 Gunungkidul, D.I. Yogyakarta, Indonesia \\ ${ }^{b}$ Department of Animal Nutrition and Feed Science, Faculty of Animal Science, Universitas Gadjah Mada \\ Jalan Fauna 3, Bulaksumur, D.I. Yogyakarta, Indonesia \\ 'Department of Parasitology, Faculty of Veterinary Medicine, Universitas Gadjah Mada \\ Jalan Fauna 2, Bulaksumur, D.I. Yogyakarta, Indonesia \\ *Email of corresponding author: kustantinah@ugm.ac.id \\ (Received 15-05-2018; Reviewed 01-08-2018; Accepted 17-09-2018)
}

\begin{abstract}
Anthelmintic resistance of Haemonchus contortus worm has become a major problem in ruminant production. Traditional medicinal and potential tropical plants with high tannin contents have a great potency as an alternative source of bio-anthelmintic. The study was carried out to assess the in vitro egg hatches inhibiting (EHI) and adult worm motility (AWM) tests and in vivo anthelmintic activities of aqueous leaf infusion of Azadirachta indica against $H$. contortus. Leaf infusion at doses of $2 \%, 4 \%$, and $6 \%$ were used for in vitro treatments, and albendazole at a dose of $2 \mathrm{mg} / \mathrm{mL}$ was used as a positive control and $\mathbf{0 . 9} \%$ of sodium chloride was used as a negative control. The EHI assay was conducted two times i.e., before treatment and $24 \mathrm{~h}$ after treatment. The AWM were monitored 15 and $30 \mathrm{~min}$, and 1, 2, 3, 4, 5, 6, 7, and $8 \mathrm{~h}$ post treatment. Sixteen Javanese Thin Tail ewes at the ages of \pm 12 months that naturally positive of $H$. contortus with about 1.000 EPG were selected and allocated randomly to 4 groups $(n=4)$. They were subsequently received the ensuing treatments i.e., $A$. indica infusion at doses of $0 \%(\mathrm{~A})$ as a control, $6 \%(\mathrm{~B}), 8 \%(\mathrm{C})$, and $5 \mathrm{mg} / \mathrm{BW}$ albendazole (D) at a single oral dose as a positive control. Experimental ewes in Groups B and C were given oral infusion weekly during 4 weeks of treatment. EPG's fecal examinations were conducted weekly. The result showed that the leaf infusion of $A$. indica containing condensed tannin (CT) at a dose of $6 \%$ significantly inhibited egg hatching $(\mathrm{P}<0.05)$ with a better effect compared to doses of $0 \%, 2 \%$, and $4 \%$. In AWM test, three doses of infusion significantly difference each other, as well as both negative and positive controls $(\mathrm{P}<0.05)$. After treatment, both of the $A$. indica containing CT levels and albendazole reduced EPG count significantly $(\mathrm{P}<0.05)$. Meanwhile, significant difference was not detected in dose of $8 \%$ aqueous leaf infusion of $A$. indica and albendazole treatments on weeks $3,4,5$, and 6 consecutively. In conclusion, the aqueous leaf infusion of $A$. indica is fully potential as a bio anthelmintic against $H$. contortus.
\end{abstract}

Keywords: Haemonchus contortus, Azadirachta indica, anthelmintic activity, leaf extract, sheep

\section{INTRODUCTION}

Haemonchus contortus called abomasum parasite is one of the nematodes which may lead to anemia that causes the decline in ruminant production resulting in economic losses (Martins et al., 2017; Pathak \& Tiwari, 2013; Gilleard, 2006). Anthelmintic treatment is applied to control this worldwide major pathological constraint. On the other hand, anthelmintic resistance of nematodes has become a major problem in many parts of the world (Ferreira et al., 2013; Costa et al., 2008; Gilleard, 2006). Because of this concern, there is a great effort to explore novel approaches for solving the problem of anthelminthic resistance by screening traditional medicinal and potential tropical plants with high tannin contents (Pathak et al., 2016; Hoste et al., 2015; Nawaz et al., 2014).

Neem tree (Azadirachta indica) popularly known as a tropical traditional medicine plant has been explored for its medicinal application. Neem leaf has been investigated to contain chemically and structurally complex active substances, i.e., nonisoprenoids include polyphenolics such as flavonoids and tannins (Adjorlolo et al., 2016; Costa et al., 2008; Subapriya \& Nagini, 2005). Condensed tannin (CT) was tested for anthelmintic activity against $H$. contortus and it was shown that CT was effective as an anthelmintic both in goat and sheep (Hoste et al., 2016; Nawaz et al, 2014; Hamad et al., 2013; Costa et al., 2008). However, the data 
on the anthelminthic activities of neem leaf reported on Javanese Thin Tail sheep, the Indonesian local sheep, are limited. Accordingly, the objectives of this study were to determine the effect of water-based leaf infusion supplementation of $A$. indica on in vitro egg hatches inhibitory effect and adult worm motility test. In addition, in vivo test was also conducted to measure the effect of $A$. indica infusion on the number of eggs per gram of feces as compared to albendazole in Javanese Thin Tail ewes.

\section{MATERIALS AND METHODS}

\section{Preparation of the A. indica Water Extract}

The mature and immature leaves (mix) of $A$. indica were collected from plants cultivated at the Research Unit for Natural Product Technology of the Indonesian Institute of Sciences, Yogyakarta, Indonesia. By following the preparation of Ferreira et al. (2013) with a slight modification, the water-base leaf extract was prepared by a simple infusion method. The fresh leaves were chopped about $\pm 1 \mathrm{~cm}$ and then dried in a freeze drying for three days at $-20^{\circ} \mathrm{C}$. The dried leaves were then ground and sheaved into 80 meshes of powder, then analyzed for CT content according to Abdulrazak \& Fujihara (1999). Two grams of triturated leaves were added with $20 \mathrm{~mL}$ of distilled water and the mixture was maintained at $2 \mathrm{~h}$, and then the mixture was ultrasonicated at $4{ }^{\circ} \mathrm{C}$ for 5 min twice by an ultrasonicator. The suspension was filtered through gauze and centrifuged at $372 \mathrm{~g}$ for $5 \mathrm{~min}$ (Odhong et al., 2014). The resulted supernatants were diluted in $0.9 \%$ of sodium chloride to a final volume of $5 \mathrm{ml}$ each with a concentration of $20 \%, 40 \%$, and $60 \%$ (with consecutive concentrations the dried leaves i.e. $2 \%, 4 \%$, and $6 \%$ ) of the leaf infusion for in vitro test. On the other hand, the stock solution was prepared in $6 \%$ and $8 \%$ concentrations to be used for the infusion in in vivo test.

\section{In Vitro Egg Hatch Inhibiting Test}

H. contortus eggs used to perform the in vitro Egg Hatch Inhibiting Test (EHIT) (Coles et al., 1992; Coles et al., 2006) were obtained from female $H$. contortus worm isolated from the abomasum of infected Javanese Thin Tail ewe ( $>1.500$ EPG). The infected ewes were slaughtered in Tegal Senggotan small ruminant abattoir in Bantul Regency. The A. indica infusion was added to the test tube exactly at the concentrations of $2 \%, 4 \%$, and $6 \%$ in a total volume of $3 \mathrm{~mL}$ of $0.9 \%$ of sodium chloride, and each concentration was replicated three times. Albendazole $(2 \mathrm{mg} / \mathrm{mL})$ was used as a positive control and $9 \%$ of sodium chloride was used as a negative control. Three adult female $H$. contortus worms were subsequently added and pulverized to each of those test tubes. The experiment was executed for $24 \mathrm{~h}$ at room temperature $\left(25-32^{\circ} \mathrm{C}\right)$. The assay was replicated two times for 0 and $24 \mathrm{~h}$ and the number of eggs were counted by following the method reported by World Association for the Advancement of Veterinary Parasitology (WAAVP), and the data were presented as $\%$ inhibition of eggs hatch, compared with two controls.

\section{In Vitro Adult-Worm Motility Test}

In vitro adult-worm motility test was conducted by following the method of Eguale et al. (2007) with modifications. Adult $H$. contortus worms were collected from abomasum of ewe slaughtered at Tegal Senggotan small ruminant abattoir in Bantul Regency. Adult worms were collected and washed and then were immediately placed in $0.9 \%$ of sodium chloride. The $A$. indica infusion was poured into the petri dishes at the concentrations of $2 \%, 4 \%$, and $6 \%$ each in a total volume of $5 \mathrm{~mL}$ of $0.9 \%$ of sodium chloride. Whilst sodium chloride $(0.9 \%)$ without infusion of $A$, indica was used as a negative control and albendazole $(2 \mathrm{mg} / \mathrm{mL})$ was used as a positive control. Each treatment was replicated 3 times. Meantime, 5 adult female worms were put into and maintained in one petri dish. Similar to the in vitro egg hatching inhibiting assay, the present experiment was conducted for $8 \mathrm{~h}$ at room temperature $\left(25-32^{\circ} \mathrm{C}\right)$. The motility of each adult worm was monitored and the percentage of motile worms was calculated after 15 and $30 \mathrm{~min}$, and on 1, 2, $3,4,5,6,7$, and $8 \mathrm{~h}$ post treatment for each treatment.

\section{In Vivo Anthelmintic Test}

Sixteen female Javanese Thin Tail ewes at the age of \pm 12 months that were naturally positively infected by $H$. contortus with EPG more than 1.000 were selected at the Research Unit for Natural Product Technology, Indonesian Institute of Sciences, Gunungkidul, Indonesia. The experimental ewes were randomly allocated into 4 groups $(n=4)$ and maintained in a sheep house and received the following treatments:

A : administered with $0.9 \%$ of $\mathrm{NaCl}$ as a control (negative control)

B : administered with $A$. indica infusion at a dose of $6 \%$ C : administered with $A$. indica infusion at a dose of $8 \%$

D : administered with Albendazole at a dose of $5 \mathrm{mg} / \mathrm{kg}$ BW (positive control)

The experimental ewes were adapted to the experimental condition for $14 \mathrm{~d}$ before the onset of treatments. In the present experiment, the treatments were given for 4 weeks after adaptation period. Groups B and C were administered with $6 \%$ and $8 \%(\mathrm{w} / \mathrm{v})$ of $A$. indica infusion orally. The calculation of the dose of $A$. indica infusion was referred to Beriajaya \& Haryuningtyas (2005) by observing the average values of abomasum fluid. Meanwhile, albendazole was given to group D as a single oral dose (Jamra et al., 2014). The experimental ewes were fed with Penissetum hybrid and wheat bran provided with water ad lib.

\section{Fecal EPG Examination}

Eggs per gram fecal (EPG) examinations were implemented on week zero before treatment and on week 1, 2, 3, and 4 post treatment. Fecal samples of each ewe were collected directly from the rectum and the eggs were counted under microscope with 100x magnification by following the McMaster modified technique according to Coles et al. (1992). 


\section{Experiment Ethical Aspects}

The experiment was carried out in accordance to the animal welfare standards. Design methods of this study had been approved by The Committee of Ethical Clearance for Pre-clinical Research of The Integrated Laboratory of Research and Testing, Universitas Gajah Mada, Yogyakarta, Indonesia with the Reference number of 00152/04/LPPT/XII/2017.

\section{Data Analysis}

The egg hatches tested and in vivo data were analyzed by using one-way ANOVA. Meanwhile the adult worm mobility tested was analyzed by factorial ANOVA, and both were continued by Duncan test to compare means. The analyses were performed by using Costat Version 6.

\section{RESULTS}

\section{Condensed Tannin Content of Azadirachta indica}

The concentrations of CT in freeze-dried young and mature leaves of $A$. indica were $3.99 \pm 1.59 \%$ and $4.15 \pm 1.18 \%$, respectively. There was no significant difference in CT contents (\%) of young and mature leaves. Therefore, the maturity of leaf did not affect the CT content. The averages of mixed $A$. indica freeze dried leaves CT content were $4.07 \pm 0.11 \%$ with $36.38 \pm 0.08 \%$ of dry matter.

\section{In Vitro Egg Hatch Test}

Egg hatches test showed that the leaf infusion of A. indica containing CT at a concentration of $6 \%$, significantly inhibited worm-egg hatching $(\mathrm{P}<0.05)$ compared with the concentrations of $2 \%$ and $4 \%$, as were shown in Figure 1. Leaf infusion containing 6\% CT showed a good anthelmintic activity with a similar activity with the albendazole as a positive control. Both of leaf infusion with a concentration of $6 \% \mathrm{CT}$ and albendazole significantly inhibited egg worm hatching $(\mathrm{P}<0.05)$. There was no statistically significant difference in the activity of $2 \%$ and $4 \%$ levels of $A$. indica leaf infusions in inhibiting worm-egg hatching compared with negative control treatment.

\section{In Vitro Adult-Worm Motility Test}

Figure 2 shows the average efficacy of the $A$. indica infusion containing $\mathrm{CT}$ to inhibit adult $H$. contortus motility (\%) during the $8 \mathrm{~h}$ of immersion. There was a statistically significant interaction of $A$. indica concentrations with the duration of treatment $(\mathrm{P}<0.05)$. Three doses of infusion significantly difference each other, as well as both of controls $(\mathrm{P}<0.05)$. The minimum adult $H$. contortus motility inhibition was found in negative control with a mortality rate was not higher than $30 \%$ over $8 \mathrm{~h}$ of observation $(\mathrm{P}<0.05)$. On the other hand, albendazole showed the best efficacy in inhibition of motility by nearly $90 \%$ mortality $(\mathrm{P}<0.05)$. The dose of $A$. indica infusion at $2 \%$ did not have CT level to reach $\mathrm{LD}_{50^{\prime}}$ except both of the $4 \%$ and $6 \%$ levels after 8 and $5 \mathrm{~h}$

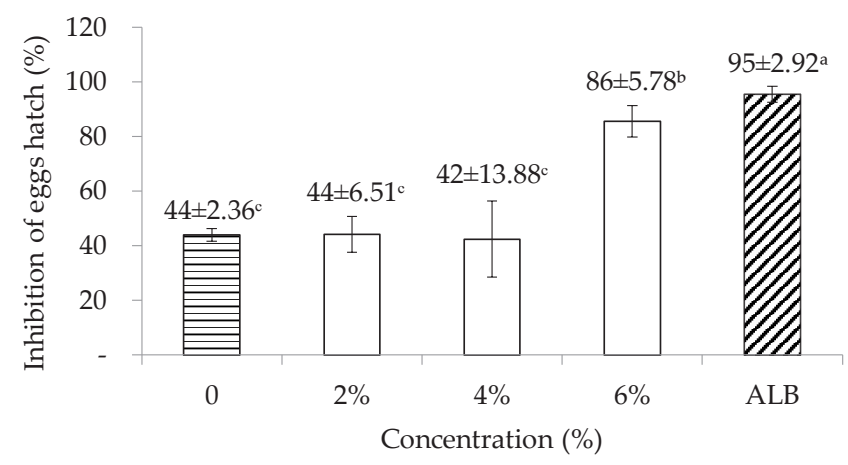

Figure 1. In vitro inhibitory effect of different leaf infusion concentrations of $A$. indica at $⿴ 10 \%, \square 2 \%, \square 4 \%$, \& $\square 6 \%$ $(\mathrm{w} / \mathrm{v})$ on egg hatch test against $H$. contortus. ALB (घ): albendazole $2 \mathrm{mg} / \mathrm{mL}$. Means with different superscripts differ significantly $(\mathrm{P}<0.05)$.

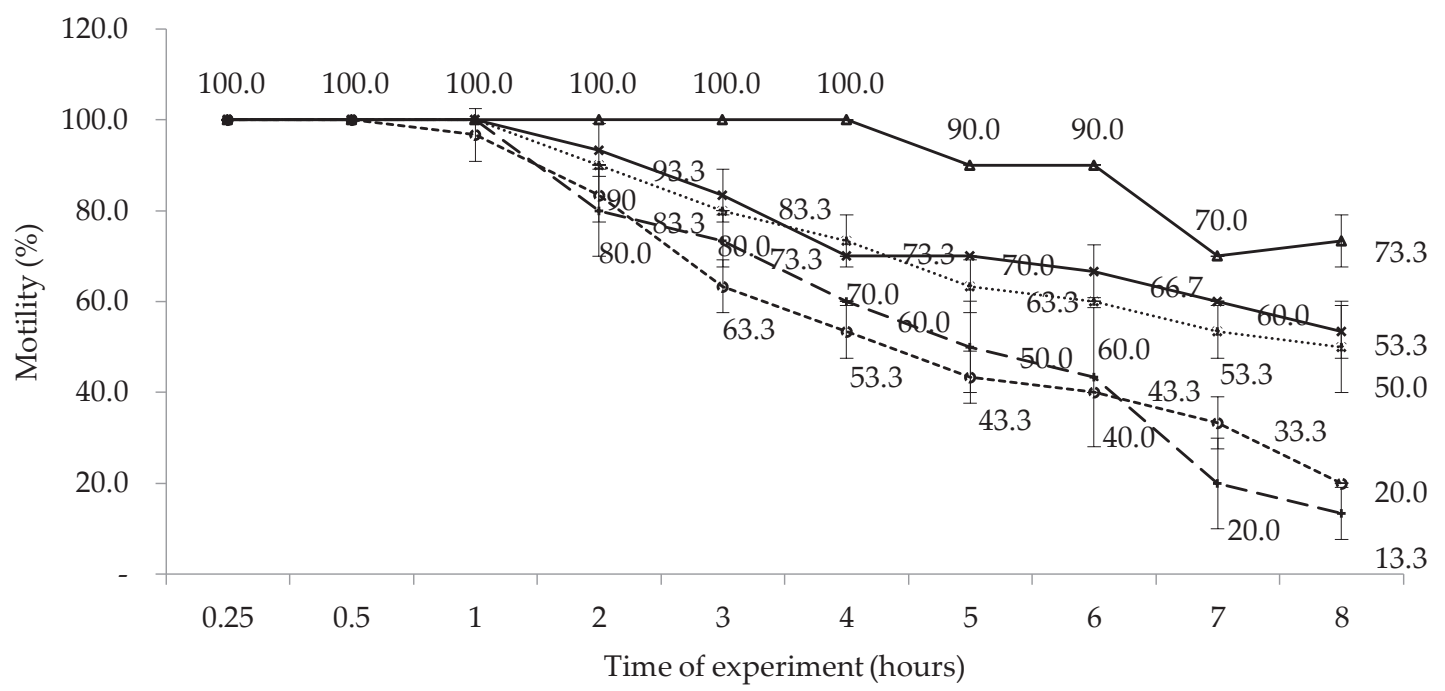

Figure 2. In vitro inhibitory effect of different leaf extract concentrations of $A$. indica $(\longrightarrow-0 \%$; $\longrightarrow 2 \% ; \cdots \cdots . . \cdots . . .4 \%$; ----4--- 6\%) on adult worm motility test against $H$. contortus. ALB $(-+-)$ : albendazole $2 \mathrm{mg} / \mathrm{mL}$. 
treatment, respectively. The effectiveness of $A$. indica leaf infusion at a dose of $6 \%$ and albendazole 8 hours after treatment were not significantly difference, which can reached $\mathrm{LD}_{50}$ after $5 \mathrm{~h}$ of immersion.

\section{In Vivo Anthelmintic Test}

Reducing of the EPG counted data are shown in Figure 3. The data showed that there was no statistically significant difference in EPG data during weeks 0-2 pre-treatment, which was an adaptation period prior to treatment. Thereafter, one week post-treatment (on week 3) both of $A$. indica containing CT levels and albendazole reduced EPG count significantly $(\mathrm{P}<0.05)$. There were significant differences in EPG in weeks 3, 4 , and 5 in ewes treated with various doses of $A$. indica leaf infusion $(6 \%$ and $8 \%$ ) and albendazole compared to control ewes. However, in week 6 of observation, the EPG counts in control ewes and ewes treated with $6 \%$ of A. indica leaf infusion were similar while those treated with $8 \%$ of $A$. indica infusion and albendazole were still different from control $(\mathrm{P}<0.05)$.

The anthelminthic effects of $8 \% A$. indica leaf infusion was similar to those of positive control (albendazole). This condition was indicated by the nonsignificant difference in EPG in ewes treated with $8 \% \mathrm{~A}$. indica leaf infusion level and albendazole in weeks 3, 4, 5 , and 6 of treatment.

There was no significant difference in EPG count in ewes treated with $6 \% \mathrm{~A}$. indica leaf infusion and albendazole on week 4 of observation. However, observation on weeks 3,5, and 6 post treatment, the anthelmintic effects of $6 \% A$. indica leaf infusion were significantly lower $(\mathrm{P}<0.05)$ than those of control positive albendazole, as were shown by the higher $(\mathrm{P}<0.05)$ EPG in ewes treated with $6 \%$ A. indica leaf infusion compared to those treated with albendazole.
Doses of $6 \%$ and $8 \%$ of $A$. indica leaf infusions had similar anthelmintic effects. There was no significant difference in EPG count in ewes treated with doses of $6 \%$ and $8 \%$ of $A$. indica leaf infusions observed on 3,4 , 5 , and 6 weeks post treatment. However, as was stated above, in week 6 of observation, the EPG counts in control ewes and ewes treated with $6 \%$ of $A$. indica leaf infusion were similar while those treated with $8 \%$ of $A$. indica infusion and albendazole were still different from control $(\mathrm{P}<0.05)$.

\section{DISCUSSION}

In this study, A. indica leaf was chosen based on the reported bio-anthelmintic potency and availability. Benzimidazoles (including albendazole) is well known for its broad-spectrum anthelmintic activity which highly effective (>95\%) against ruminant parasites. However, the uses of albendazole lead to the resistance of nematodes to the albendazole, especially $H$. contortus (Rezansoff et al., 2016). The resistance has been widespread globally due to the frequent use and the time of their availabilities (Besier et al., 2016; Martins et al., 2017). Based on these resistance factors, searching of the bio-anthelmintic plant extracts may contribute to the novel development of traditional plant-based remedies that could provide a lower risk of resistance than the chemical anthelmintic (Ferreira et al., 2013; Besier et al., 2016). Aqueous infusion, based on this research with $A$. indica, and according to the previous study using the other traditional plant containing CT (Vieira et al., 2017; Nawaz et al., 2014; Ferreira et al., 2013; Eguale et al., 2007), tannin clearly inhibited egg hatching and adult worm motility. These facts then allowed that aqueous extract method could be used in the preparation of bio anthelmintic source in anthelmintic research work. The efficacy of $6 \% A$. indica leaf infusion was better than

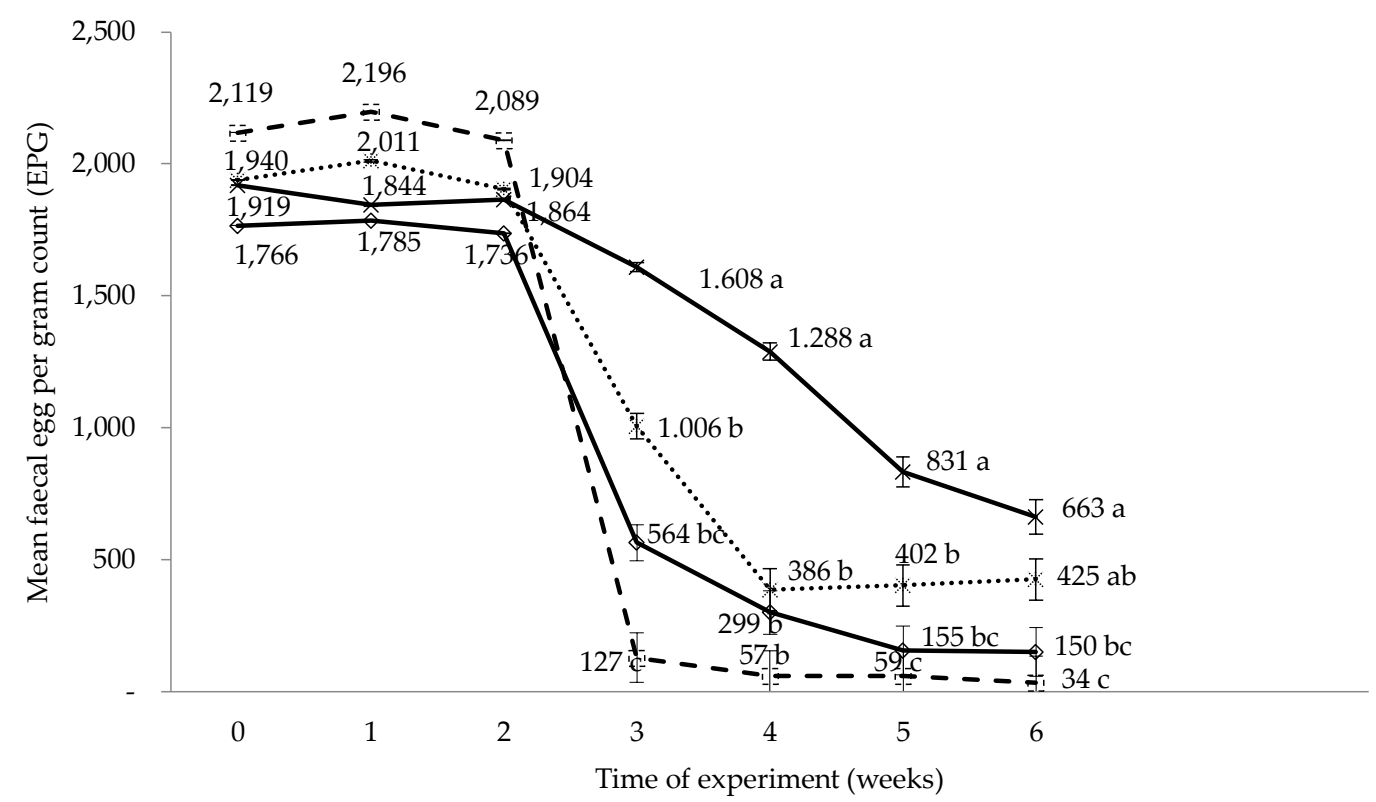

Figure 3. In vivo anthelmintic activity of different leaf extract concentrations of $A$. indica: $0 \%$ (Control negative, $\rightarrow *$ ), $6 \%$ ( (...*...), $8 \%$ $(\smile$ ), and Albendazole $5 \mathrm{mg} / \mathrm{BW}$ (Control positive, - - - ) on mean faecal egg per gram count of Javanese thin tail ewes. Means with different superscripts $\left({ }^{a, b}, c\right)$ at same time of experiment were differ significantly $(\mathrm{P}<0.05)$. 
those of $0 \%, 2 \%$, and $4 \%$. The dose of $6 \%$ indicated a substantial potency of $A$. indica as a good bio-anthelmintic activity to inhibit worm-egg hatching. Similar to this study for about $5 \%-6 \%$ levels of leaf simple infusion reported egg-hatching inhibition until 84.91\% in Annona muricata at 5\% (w/v) against H. contortus (Ferreira et al., 2013).

This study did not only conduct in vitro study, but also in vivo experiment. In vitro model gave advantage that compounds of plant contacted and affected the target process freely and directly e.g., egg stage of $H$. contortus. However, effectiveness of plant material that is tested in vitro does not always show an equally effective result in vivo (Ferreira et al., 2013). This study used Javanese thin-tailed sheep, a native breed of small ruminant in Indonesia. Javanese thin-tailed sheep is considered to be a more suitable breed for grazing system (Budisatria et al., 2007). On the other hand, small ruminant with grazing behavior may be susceptible to infection, especially $H$. contortus, one of the most important representatives of the order Strongylida in tropical and subtropical areas (Gasser et al., 2016).

EPG count data on in vivo adaptation period were not different due to the implementation of the similar feed ration to all of treatments. The non-significant EPG count was also contributed by feeding a cultivation grass type such as $P$. hybrid that might be expected to have a fewer larvae of parasites contamination than a field grass. Owing to the fact that $P$. hybrid cultivation area has a limited contact with susceptible animals, different from the non-rotational pasture system. This condition leads to a slowing down of the ewe-infection dynamics (Besier et al., 2016; Hoste et al., 2006; Paolini et al, 2003).

The test based on EPG count confirmed a statistically significant reduction in one weeks post-treatment (on week 3 ). Both levels of $A$. indica infusion could produce a similar result with albendazole. The anthelmintic efficacy of $A$. indica against $H$. contortus is related to the presence of CT. Recently, the novel research involving the supplementing of forages containing CT to ruminants has been focused on the utilization of anthelmintic activities (Nauman et al., 2013). Condensed tannins of the leaf extract damage the cuticle of $H$. contortus (Tresia et al., 2016) which can bind the parasite's cuticle protein (Kerboeuf et al., 2008), that may lead to the reduction of the flavonoid diffusion and increase the exposure to the compound (Tresia et al., 2016). The fatal intracellular consistency occurred due to the inhibition of enzyme secretion by CT that would cause a paralysis of parasites (Tresia et al., 2016; Kerboeuf et al., 2008; Hoste et al., 2006).

Nevertheless, the effectiveness of treatments did not persist during a long period, which was found the similarity of efficacy at $6 \%$ on week 6 compared to negative control. The reduction on EPG count in ewes treated with negative control might be affected by nutrition factor, as a consequence of implementation of forages and wheat bran which had a $19.15 \%$ dry matter (DM) of crude protein (Jayanegara et al., 2017). Indirect effect on $H$. contortus biology is the presence of adequate dietary nutrient of the digestive content that improves the host's immune response systems against the parasites (Hoste et al, 2016). There is a significant relationship between nutrition and infection (Pathak \& Tiwari, 2013). The host ability to control any parasites can be affected by the enhanced nutrition and the levels of protein and energy (Pathak \& Tiwari, 2013; Maherisis et al., 2011; Athanasiadou et al., 2001). Most of the CT at $6 \%$ and $8 \%$ $A$. indica present in feed in the rumen of ewes would be expected to form complexes with the dietary protein leading to an improvement of host's immune response against $H$. contortus (Hoste et al, 2016; Athanasiadou et al., 2001).

\section{CONCLUSION}

The aqueous leaf infusion of $A$. indica at doses of $6 \%$ and $8 \%$ showed in vitro and in vivo anthelmintic activities against $H$. contortus by reducing egg hatch, adultworm motility, and the count of egg per gram feces as from one weeks post-treatment (on week 3) on in vivo test. The infusion of $A$. indica is fully potential as a bio anthelmintic against $H$. contortus.

\section{CONFLICT OF INTEREST}

The authors ensure that have no financial and personal conflict of interest.

\section{ACKNOWLEDGEMENT}

The authors would like to convey their fully thanks to the Feed BPTBA-LIPI Laboratory, IMT Laboratory of Animal Husbandry Faculty, UGM, and Parasitology Laboratory of Veterinary Medicine Faculty, UGM for supporting this research. The authors also appreciate the supporting technical assistance of Mrs. Siti (UGM), Ms Melisa Eka Ningrum (LIPI), Mr Diding Ristino (LIPI), Ms Lovy Perdani (UGM student), Mr Raka (UII student) and Mr Arib (UAD student) for their fully helps during all of in vitro and in vivo assays.

\section{REFERENCES}

Abdulrazak, S. A. \& T. Fujihara. 1999. Animal Nutrition: A Laboratory Manual. Laboratory of Animal Science. Faculty of Life and Enviromental Science. Shimane University. Japan. 1: $24-28$.

Adjorlolo, L. K., E. C. Timpong-Jones, S. Boadu, \& T. AdoglaBessa. 2016. Potential contribution of neem (Azadirachta indica) leaves to dry season feeding of ruminants in West Africa. Livest. Research R. Dev. 28: 1-9.

Athanasiadou, S., I. Kyriazakis, F. Jackson, \& R. L. Coop. 2001. The effect of condensed tannins supplementation of foods with different protein content of parasitism, food intake, and performance of sheep infected with Trichostrongylus colubriformis. British J. Nut. 86: 697-706. https://doi. org/10.1079/BJN2001468

AOAC. 2005. Official Methods of Analysis of AOAC International. 18th ed. Assoc. Off. Anal. Chem., Arlington.

Beriajaya, J. M. \& D. Haryuningtyas. 2005. Efficacy of pineaaple skin extract to control Haemonchus contortus on Sheep. Husbandry Technology and Veteriner National Seminar. 934-940.

Besier, R. B., L. P. Khan, N. D. Sargison, \& J. A. Van Wyk. 2016. 
Diagnosis, treatment and management of Haemonchus contortus in small ruminants. Chapter Six. Adv. Parasitol. 93: 181-238. https://doi.org/10.1016/bs.apar.2016.02.024

Budisatria, I. G. S., H. M. J. Udo, C. H. A. M. Eilers, \& A. J. van der Zijpp. 2007. Dynamic of small ruminant production a case study of Central Java, Indonesia. Agriculture. 36: 145-152.

Coles, G. C., C. Bauer, F. H. M. Borgsteede, S. Geerts, T. R. Klei, M. A. Taylor \& P. J. Waller. 1992. World Association for the Advancement of Veterinary Parasitology (W.A.A.V.P.) methods for the detection of anthelmintic resistance in nematodes of veterinary importance. Vet. Parasitol. 44: 3544. https://doi.org/10.1016/0304-4017(92)90141-U

Coles, G. C., F. Jackson, W. E. Pomroy, R. K. Prichard, G. Von Samson-Himmelstjerna, A. Silvestre, M. A. Taylor, \& J. Vercruysse. 2006. The detection of anthelmintic resistance in nematodes of veterinary importance. Vet. Parasitol. 136: 167-185. https://doi.org/10.1016/j.vetpar.2005.11.019

Costa, C. T. C., C. M. L. Bevilaqua, A. L. F. Camurça-Vasconcelos, M. V. Maciel, S. M. Morais, C. M. C. Castro, R. R. Braga, L. M. B. Oliveira. 2008. In vitro ovicidal and larvacidal activity of Azadirachta indica extracts on Haemonchus contortus. S. Rum. Research. 74: 284-287. https://doi.org/10.1016/j. smallrumres.2007.09.003

Eguale, T., G. Tilahun, A. Debella, A. Feleke, \& E. Makonnen. 2007. In vitro and in vivo anthelmintic activity of crude extracts of Coriandrum sativum against Haemonchus contortus. J. Ethnophar. 110: 428-433. https://doi.org/10.1016/j. jep.2006.10.003

Ferreira, L. E., P. M. N. Castro, A. C. S. Chagas, S. C. França, \& R. O. Beleboni. 2013. In vitro anthelmintic activity of aqueous leaf extract of Annona muricata L. (Annonaceae) against Haemonchus contortus from sheep. Exp. Parasitol. 134: 327-332. https://doi.org/10.1016/j.exppara.2013.03.032

Gasser, R.B., E.M. Schwarz, P.K. Korhonen, \& N.D. Young. 2016. Understanding Haemonchus contortus better through genomics and transcriptomics. Adv. Parasitol. 93: 519-547. http://dx.doi.org/10.1016/bs.apar.2016.02.015

Gilleard, J. S. 2006. Understanding anthelmintic resistance: the need for genomics and genetics. Int. J. Parasitol. 36: 12271239. https://doi.org/10.1016/j.ijpara.2006.06.010

Hamad, K. K., Z. Iqbal, Z. D. Sindhu, R. Z. Abbas, A. Khan, G. Muhammad, \& B. Epperson. 2013. Combination of Nicotiana tabacum and Azadirachta indica: a novel substitute to control levamisole and ivermectin-resistant Haemonchus contortus in ovine. Pak. Vet. J. 34: 24-29.

Hoste, H., F. Jackson, S. Athanasiadou, S. M. Tamsborg, \& S.O. Hoskin. 2006. The effect of tannin-rich plants on parasitic nematodes in ruminants. Trends Parasitol. 22: 253-261. https://doi.org/10.1016/j.pt.2006.04.004

Hoste, H., J. F. J. Torres-Acosta, J. Quijada, I. Chan-Perez, M. M. Dakheel, D. S. Kommuru, I. Muller-Harvey, \& T. H. Terrill. 2016. Interactions Between Nutrition and Infections with Haemonchus contortus and Related Gastrointestinal Nematodes in Small Ruminants. Adv. Parasitol. 93: 239351. https://doi.org/10.1016/bs.apar.2016.02.025

Hoste, H., J. F. J. Torres-Acosta, C. A. Sandoval-Castro, I. Mueller-Harvey, S. Sotiraki, H. Louvandini, S. M. Thamsborg, \& T. H. Terrill. 2015. Tannin containing legumes as a model for nutraceuticals against digestive parasites in livestock. Vet. Parasitol. 212: 5-17. https://doi. org/10.1016/j.vetpar.2015.06.026

Jamra, N., G. Das, P. Singh, \& M. Haque. 2014. Anthelmintic efficacy of crude neem (Azadirachta indica) leaf powder against bovine strongylosis. J. Parasitic Diseases. 39: 786788. https://doi.org/10.1007/s12639-014-0423-9
Jayanegara, A., M. Ridla, D. A. Astuti, K. G. Wiryawan, E. B. Laconi, \& Nahrowi. 2017. Determination of energy and protein requirements of sheep in Indonesia using metaanalytical approach. Med. Pet. 40: 124-133. https://doi. org/10.5398/medpet.2017.40.2.118

Kerboeuf, D., M. Riou, \& F. Guegnard. 2008. Flavonoid and Related Compounds in Parasitic Disease Control. Mini. Rev. Med. Chem. 8: 116-128. https://doi. org/10.2174/138955708783498168

Maherisis, N., M. C. Semsari, B. Eshratkhah, M. Sadaghian, A. Gorbani \& S. Hassanpour. 2011. Evaluation of the effects of Quebracho condensed tannin on faecal egg counts during naturally acquired mixed nematode infections in Moghani sheep. Annals Biol. Res. 2: 170-174.

Martins, A. C., P. L. F. Bergamasco, G. Felippelli, J. H. Tebaldi, M. F. D. Moraes, A. J. P. Testi, I. M. Lapera, \& E. G. L. Hoppe. 2017. Haemonchus contortus resistence to monepantel in sheep: fecal egg count reduction tests and randomized controlled trials. Semina: Ciencias Agr. 38: 231-238.

Naumann, H. D., J. P. Muir, B. D. Lambert, L. O. Tedeschi, \& M. M. Kothmann. 2013. Condensed tannins in the ruminant environment: a perspective on biological activity. J. Agr. Sci. 1: 8-20.

Nawaz, M., S. M. Sajid, M. Zubair, J. Hussain, Z. Abbasi, A. Mohi-Ud-Din, \& M. Waqas. 2014. In vitro and In vivo anthelmintic activity of leaves of Azadirachta indica, Dalbergia sisso and Morus alba against Haemonchus contortus. Global Vet. 13: 996- 1001.

Odhong, C., R. G. Wahome, M. Vaarst, S. Nalubwama, M. Kiggundu, N. Halberg, \& S. Githigia. 2014. In vitro anthelmintic effects of crude aqueous extracts of Tephrosia vogelii, Tephrosia villosa, and Carica papaya leaves and seeds. Afr. J. Biotechnol. 13: 4667-4672. https://doi.org/10.5897/ AJB2014.14048

Paolini, V., J. P. Bergeaud, C. Grisez, F. Prevot, Ph. Dorchies, \& H. Hoste. 2003. Effect of condensed tannins on goats experimentally infected with Haemonchus contortus. Vet. Parasitol. 113: 253-261. https://doi.org/10.1016/ S0304-4017(03)00064-5

Pathak, A. K., N. Dutta, P. S. Banerjee, T. K. Goswami, \& K. Sharma. 2016. Effect of condensed tannins supplementation through leaf meal mixture on voluntary feed intake, immune response and worm. J. Parasit Dis. 40: 100-105. https://doi.org/10.1007/s12639-014-0455-1

Pathak, A. K. \& S. P. Tiwari. 2013. Effect of high plane of nutrition on the performance of Haemonchus contortus infected kids. Vet. World. 6: 22-26. https://doi.org/10.5455/ vetworld.2013.22-26

Rezansoff, A. M., R. Laing, \& J. S. Gilleard. 2016. Evidence from two independent backcross experiments supports genetic linkage of microsatellite Hcms8a20, but not other candidate loci, to a major ivermectin resistance locus in Haemonchus contortus. Intl. J. Parasitol. 46: 653-661. https:// doi.org/10.1016/j.ijpara.2016.04.007

Subarpriya, R. \& S. Nagini. 2005. Medicinal Properties of Neem Leaves: A Review. Curr. Med. Chem. 5:149-156.

Tresia, G. E., D. Evvyernie, \& R. Tiuria. 2016. Phytochemical Screening and in Vitro Ovicidal, Larvacidal, and Nematicidal Effects of Murraya paniculata (L.) Jack Extract on Gastrointestinal Parasites of Goats. Med. Pet. 39: 173179. https://doi.org/10.5398/medpet.2016.39.3.173

Vieira, T. M., L. D. Fonseca, G. A. Bastos, V. O. Vasconcelos, M. L. F. Silva, F. Morais-Costa, A. V. P. Ferreira, N. J. F. Oliveira, \& E. R. Duarte. 2017. Control of Haemonchus contortusi in sheep using basidiocarps of Agaricus blazei Murril. Vet. Res. Commun. 41: 99-106. https://doi.org/10.1007/ s11259-017-9677-x 